\title{
Aristotle, Vision, and \\ Communicable Change
}

\author{
Micah Bailey \\ University of Kansas
}

\section{$\S 1$. Introduction}

In De Anima, Aristotle states: "one must understand that the sense is that which is receptive of the sensible forms without the material" (DA, 424a1719). However, as W.V. Wilkes puts it in her PsuchēVersus the Mind:

it is, to put it mildly, hard to understand Aristotle's insistence that perceiving and thinking is a matter of 'receiving the form' and becoming 'identical with its object' (EADA, 126).

To put it mildly, I agree. Some interpreters (specifically M.F. Burnyeat) take it that, for Aristotle, awareness is primitive and no material or physiological process of a sense organ is necessary for perception. Other interpreters (specifically Hilary Putnam \& Martha Nussbaum) take it that, for Aristotle, even though the soul (psuchē) is not reducible to material or physiological processes of a sense organ, such processes are necessary for the realization of perception. In this paper, I provide further support to Putnam \& Nussbaum's position, although I do not go so far as to claim that their position is the correct one; rather, I focus on criticizing Burnyeat. In particular, to open up room for his interpretation, Burnyeat seems to find it necessary, in "How Much Happens When Aristotle Sees Red and Hears Middle C?”, to interpret the process involved in vision as being no process at all. It is this interpretation of vision I will be arguing against.

First, I provide a general sketch of Aristotle's theory of soul and his formmatter distinction, because it will help us understand Aristotle's theory of perception (which vision is a part of) and how such differing interpretations of it can arise. Second, I provide fuller accounts of Putnam \& Nussbaum and Burn- 
yeat's respective interpretations of Aristotle, as this will clarify what is at stake. Last, I provide not only what I take to be a very general sketch of the key components for Aristotle when it comes to vision, but also the naïve (i.e. natural) way to interpret him. Then I examine how Burnyeat deals with the problems that the naïve interpretation presents his own interpretation; and via this investigation Burnyeat's interpretation of Aristotle's theory of vision is revealed, and as it emerges, I criticize it and give my own account of Aristotle's theory of vision. Moreover, I anticipate and treat a couple of possible objections that Burnyeat might make.

\section{§2. Aristotle's Theory of Soul, Form-Matter Distinction, and Theory of Perception}

\section{\$2.1. Aristotle's Theory of Soul}

The starting point for understanding Aristotle's theory of perception is understanding how perception fits in with the rest of De Anima. In De Anima, Aristotle is providing his own account of the soul (psuchē). This should not be confused for what is typically conceived of as the soul today; as some ethereal thing that lives on after death, enjoying a rich cognitive life. Instead, Aristotle claims that the soul is "the form of a natural body that has life as its potency" (DA, 412a19). To break down this statement, we need to have a basic understanding of what Aristotle means by 'form', 'body', and 'potency'.

For Aristotle, there are three substances: form, material, and the composite of form and material. ${ }^{1}$ Form is the essence of a thing; it is what makes an object the particular type of object that it is, and what type an object is can be determined by its shape and function. For instance, if an object is shaped such that it has a handle and a head with a sharp edge, and if that object's function is to chop wood, then the object in question is an axe. Or, if an object is shaped such that it is spherical, and if that object has the function of seeing, then that object is an eye. ${ }^{2}$ Now, material is the matter of a type of object. For instance, it's both the wood that makes up the axe-handle and the iron that makes up the axe-head that, in turn, make up the axe. Or, it is the water and eye-jelly (i.e., eyeball) that makes up an eye. The composite, on the other hand, is the conjunc-

1 'Substance' here does not mean an independently existing thing or substratum (EADA, 58).

${ }^{2}$ Perhaps in this case, it doesn't matter what the shape of the thing is, but only that its function is to see; in which case, it's an eye. 
tion of form and matter into a unity; for example, the axe and eye just discussed are composite objects; indeed, Aristotle notes that "[t]here is no need... to inquire whether soul and body are one" (DA, 412b5). And so, we see, for Aristotle, that composite objects have two aspects to their being: form and matter.

Now we can better understand Aristotle's definition of 'soul'. First, the composite bodies in question are living bodies; these turn out to be particular plants, animals, or humans. The material of these composite bodies have the potential or power to be living, which is what is meant by 'potency'. The soul, on the other hand, is the essence of living things; that is, the soul is what makes plants, animals, and humans living things, and it explains the biological or mental functions of plants, animals, and humans. Specifically, the soul explains three general functions of living things. The intellective soul accounts for thought and understanding, which only humans have. The perceptive soul accounts for touch, taste, smell, sight, and hearing; all and only animals have touch, including humans, but some animals have some additional combination of these perceptive powers. The nutritive soul is the most basic; it accounts for growth, decline, reproduction, and the assimilation of food. All living things, including plants, have a nutritive soul.

\section{§2.2. Form-Matter Distinction}

Given Aristotle's definition of soul, and given that one of the functions that the soul explains is that of perception, we see that soul will play a vital role in Aristotle's theory of perception. But it is Aristotle's distinction between form and matter that has caused so much interest in how his theory of perception unfolds. First of all, the form-matter distinction doesn't break down into the Cartesian mind-body distinction; otherwise, as Wilkes notes, we'll have to admit that grass has a mind, since grass has a form (EADA 113). Moreover, Aristotle will not be giving us a reductionist account of perception. This is the case, as even though form and matter are always found unified within a composite object and are thus, in some sense one, Aristotle takes them to be ontologically distinct. He classifies form as an immaterial substance, while claiming that matter is a material one. Therefore, the reductionist claim (that the matter of an object determines its nature or essence) is not open to Aristotle, since, on his view, it is the form and not the matter that determines an object's essence. That means concerning vision, it cannot be that Aristotle wants to claim that seeing just is certain physiological processes in the eyeball, brain, or heart. But if not Cartesian dualism, and if not some reductionism (e.g., a type identity theory), 
what does Aristotle's account of perception look like?

\section{§2.3. Theory of Perception}

Just because reductionism is off the table, it doesn't follow that some material or physiological process in the sense organ is not necessary for perception. And just because Cartesian dualism is off the table, it doesn't follow that perception doesn't occur solely on the level of awareness, without the need of any material or physiological process. It is the former consequence that opens the playing field to Putnam \& Nussbaum's interpretation of Aristotle's theory of perception, while it is the latter consequence that opens the same playing field to Burnyeat's interpretation of Aristotle's theory of perception. Now that we have grasped why two contrary interpretations of Aristotle's theory of perception is at least initially possible, let us turn to filling out what those interpretations are.

\section{\$3. Putnam \& Nussbaum and Burnyeat's Interpretations of Aristotle's Theory of Perception}

\section{§3.1. Putnam \& Nussbaum's Interpretation}

First we will consider Putnam \& Nussbaum's interpretation. In Changing Aristotle's Mind, Putnam \& Nussbaum say the following:

Metaph. ZII asserts the point unconditionally about animals... 'For the animal is a perceptible thing, and it is not possible to define it without change, therefore not without the bodily parts' being in a certain condition' (1036 $27 \mathrm{ff}$.). The inferential pattern ... suggests that Aristotle makes an intimateindeed a necessary - connection between change and materiality ... [I]t was apparently taken for granted that change is something that goes on in materials, and indeed that what matter is is the vehicle of change.

We believe that this is still a reasonable position (although we do not go so far as to identify change with matter). In our conception, any being that undergoes change is a material being. We cannot prise these two things apart, even in thought, without incoherence. From this it follows that any account that properly gives the what-is-it of such a being must make 
mention ... of the presence of material composition that is in some way suitable or in the right state. This tells us that on pain of incoherence we cannot describe the natural functions that are the essential natures of animals and plants without making these functions (even if only implicitly) embodied in some matter that is suitable to them: matter that is not simply an inert background, but the very vehicle of functioning itself.

All of this is supposed to be true of all the essential being and doings of natural substances; a fortiori (apparently) of the being and doings of living creatures; a fortiori (one might suppose) of perceiving. (EADA, 32)

The first paragraph of this passage tells us that if change or movement is part of the essence of a thing (which it is for animals), then it is impossible to give the essence of the thing without referring to its material states. Since, the essence of a thing is cashed out in terms of its function (i.e., form), then it follows that to explicate the functions of animals, one must include talk of the material composition of the animal's parts. And since perceiving is a function of animals, then, to give those functions, one must also give the material compositions of eyeballs, ears, etc. According to Putnam \& Nussbaum, this is not to claim that the material composition of a sense organ is identical with the perception, for that would make Aristotle a reductionist; instead, the material composition of the sense organ constitutes or realizes the perception. Thus, if there is a change in perception, then there must have been a change in the sense organ, which has the significance of having Aristotle support the functionalist solution to the mind-body problem. ${ }^{3}$

What is significant to this paper is that this commits Putnam \& Nussbaum to interpreting Aristotle as claiming that the effect a sensible object (e.g., color) has (through some medium) on a sense organ (e.g., eye) amounts to a real change or alteration; for without a real change or alteration in the sense organ there would be no change in perception corresponding to the sensible object's effect. Even though in Changing Aristotle's Mind, Putnam and Nussbaum use different evidence from what I offer below in $\S 4$ to argue that the effect of sensible objects is indeed a real alteration, I leave it up to the reader to review their arguments.

${ }^{3}$ Though, this is not to claim that Aristotle is a full-fledged functionalist, but instead, that he and functionalists coincide on this matter. 


\section{$\S 3.2$. Burnyeat's Interpretation}

Now we consider Burnyeat's interpretation. He states that there is: no physiological change is needed for the eye or the organ of touch to become aware of the appropriate perceptual objects. The model says: the effect on the organ is the awareness, no more and no less. This second point is the one that is puzzling from a modern point of view, the one that is inimical to the Putnam-Nussbaum assimilation of Aristotle to modern functionalism, for it means that in a certain sense an animal's perceptual capacities do not require explanation. For Aristotle such capacities are part of animal life and in Aristotle's world the emergence of life does not require explanation... The secondary qualities (so called by us) are already out there in his world, fully real; these are the sensible forms. All that is needed for perception to take place is for these qualities or forms to act on the corresponding faculties in us to bring about an awareness of themselves... Not merely is there no deduction from physiology to perception, not merely are there no physiological sufficient conditions for perception to occur, but the only necessary conditions are states of receptivity to sensible form: transparent eye-jelly, still air walled up in the ear, intermediate temperature and hardness in the organ of touch. When these have been specified, the material side of the story of perception is complete. That, at any rate, is my thesis about what Aristotle's thesis about perception is. (EADA, 22-3)

Thus, for Burnyeat's interpretation, awareness is to be taken as primitive. As a result, no physiological process is necessary. The significance of Burnyeat's interpretation is that Aristotle's theory of perception cannot solve the mindbody problem, since perception does not require explanation. Thus, Putnam \& Nussbaum's appropriation of Aristotle to the functionalist solution of the mindbody problem is a mistake, or so says Burnyeat.

But note that Burnyeat does say that, for perception to take place, some material conditions are necessary; namely, certain material states must be re- 
ceptive to sensible forms. Intuitively, however, if these material states are receptive to sensible forms, then the sensible forms can act upon them. And, if these material states are acted upon, it is intuitive to think that the action changes them; thus, there is prima facie reason for thinking that a physiological process must occur to have perception. This is why, in my view, Burnyeat tries show that in perceiving (including vision), the action of the sensible forms amounts to no real action or process at all. We would do well to turn to sketching a general interpretation of Aristotle's theory of vision. After which, we can flesh out Burnyeat's interpretation of it; providing criticism of his view.

\section{\$4. A General and Naïve Sketch of Aristotle's Theory of Perception, Burnyeat's Interpretation, and My Criticisms}

\section{§4.1. A General and Nä̈ve Sketch}

It should be kept in mind that in what follows in this paragraph is supposed to be a naïve reading of Book II chapter 7 of De Anima (See 418a25-419b2). Such a reading claims that, for Aristotle, at least these three things are necessary for there to be sight: one, a living eye; two, an actualized transparent medium; and three, color. Let's consider how these work together for vision to occur. First, the color is the proper object of sight, and it is external to the eye. The nature of color is to set the actualized transparent medium into motion; thus, the color is the actor, while the transparent medium is what is being immediately moved. Second, the transparent medium is a property of both air and water. In its potentiality, the transparent medium is dark and color cannot be seen. Light actualizes the transparent medium; and so, color only acts on the transparent medium when it is illuminated. Third, the eye is made up of eye-jelly, which is mostly made of water. Recall that the transparent medium is not only a property of air, but of water too; and so, the transparent medium within the eye is mediately moved by the color via the transparent medium that's outside the eye, which the color had immediately moved. Thus, on the naïve reading, we see that, for Aristotle, the movement in question occurs within the eye; that is, on the naïve reading, it seems we have a physiological process. Our question, then, is what does this movement amount to?

\section{\$4.2. Burnyeat's Interpretation of 'Movement'}

In book II chapter 5 of De Anima, Aristotle states both that "perception involves being moved and undergoing something" and later that "all things are 
acted upon and moved by what already is at work and productive of motion" (DA, 416b30 \& 417a18). Talk of "being moved" and being "acted upon" implies suggests material change. If, for perception to take place, it is necessary that a sense organ be acted upon such that one of its components must be moved, then Burnyeat's interpretation will be manifestly wrong, since such a movement would be a physiological process.

But Burnyeat points out that what has been translated into 'movement' is 'kinēsis' (EADA, 424). He says that this is deeply misleading, because "we must not understand 'motion' as 'locomotion'”, for “[k]inēsis in Aristotle's usage is the generic term for all kinds of change, including alteration. . . . [And] kinētikon just means 'productive of a change', not 'productive of spatial movement'” (ibid.). Thus, to say that color moves the transparent medium is not to say that color moves the medium from one spatial location to another; instead, what can be inferred is that color affects some sort of change upon the medium. And since the color mediately affects the eye via the transparent medium, we can infer, at best, that the color affects some sort of change upon the eye, but we cannot yet infer that that change is locomotive. In this way, Burnyeat successfully dodges the charge that Aristotle means for the color to spatially move parts of the eye, which would clearly be a physiological process. But if parts of the eye undergo change, even if it isn't a change in spatial location, then it might still be argued that that change amounts to a physiological process; indeed, that is precisely the avenue Putnam \& Nussbaum take (See EADA, 37-41).

\section{$\S 4.2$. Burnyeat's Interpretation of Vision and Quasi-Alteration}

To avoid the charge that the change in question is still a physiological process even though its not a movement, Burnyeat interprets the process of sight such that the change doesn't refer to a real alteration, and thereby, not a real process (EADA, 425). First, Burnyeat points out that, on Aristotle's account, light doesn't travel; moreover, light is not only the actuality of the transparent medium, but it is what makes color go from potentially being present to actually being present (EADA, 424). Thus, Burnyeat concludes, that the effect of color doesn't travel either; it just instantaneously appears through the transparent medium when it's illuminated, and this “appearing through" just is the effect color has on the transparent medium and is no real alteration (EADA, 425). On this Burnyeat states:

$[w]$ hen the medium is actually transparent (diaphanes), i.e. when the medium is such that colours can appear through 
it (phainesthai dia), they do appear through it. At the same time, the transparent itself, the light, becomes visible in a way and coloured in a way-without being really coloured and, in consequence, without undergoing a real alteration. This non-real alteration - a quasi-alteration I shall call it - of the transparent consists in the fact that colours appear through it. (ibid.)

The effect of color seems to be a quasi-alteration for two reasons. First, since the effect of color is instantaneous with the illumination of light, no process takes place; instead, the state of affairs is static (EADA, 424). And, since a physiological process is a process, if no process is to be had, then no physiological process is to be had either. Second, the transparent medium isn't really colored (EADA, 425). To understand this second point, consider the example Burnyeat gives for illustration (EADA, 425-6). Suppose you put your eye up to a bowl of water and a red object is placed on the other side of the bowl. From your point of view, you will see the color red, but note that slightly changing the angle makes it such that the red will no longer be viewable. On the other hand, if the water were to be dyed red, then you could see the red color no matter the angle you viewed the bowl. The reason you can see red on the latter situation is because the water (i.e., the transparent medium) has literally been affected (i.e., a real change or alteration has taken place); however, the reason you don't see red at every angle in the former condition is because it hasn't literally been affected (i.e., no real change or alteration has taken place).

\section{§4.3. My Criticisms and Considered Objections}

As far as I can see, there are two reasons for thinking this account can be plausibly ascribed to Aristotle. First, it does justice to why Aristotle labels the medium 'transparent', since what is transparent just is that which other objects can appear through. Second, although Aristotle claims that "perception involves being moved and undergoing something", he clearly thinks the "alteration" is not alteration in the standard sense; indeed 'being acted upon' and 'being altered' aren't even the correct terms according to Aristotle, but he uses them because no other term suffices (DA, 418a1-8). Since Burnyeat holds that the "alteration" is not a real alteration, it would seem that his reading of Aristotle accords well. 
However, I find there to be many concerns with Burnyeat's rendering. First, he doesn't sufficiently show that a process doesn't take place when the transparent medium is illuminated. That's because Burnyeat's scope for a process is too small. For example, consider two contiguous instants of time, $\mathrm{t}_{1}$ and $t_{2}$. At $t_{1}$ we have an eye in darkness, perceiving no color. At $t_{2}$, we have the same eye in light perceiving color. Even if there is no process at $t_{2}$, because it is but an instant of time, it is still reasonable to ask whether the physiology of the eye at $\mathrm{t}_{1}$ is different than its physiology at $\mathrm{t}_{2}$; and, if the eye's physiology does differ between those times, it's reasonable to ask whether the light and color caused that difference and whether the difference was necessary for perception. In short, although $t_{2}$ doesn't amount to a process, $t_{1}$ to $t_{2}$ does.

\section{\$4.3.2. Recollecting in the Dark}

Second, Aristotle says: "perception originates from things present, whereas recollection, proceeding from the soul, results in either motions in the organs of sense or in persisting states of them" (DA, 408b15-20). If it's the function of recollection to conjure up images of past perceptions without the object of perception being present, it's certainly interesting that doing so results in "motions" in the sense organs (or persisting states of them). The suggestion seems to be that to be aware of images, there must be motion in the sense organs, independent of whether the images one is aware of is to be characterized as perceptions or recollections; if perception is primitive, Aristotle would have no need to insist that recollection results in the motion of the sense organs. But, if that is the case, then it cannot be that the "alteration" in question merely amounts to the color appearing through the illuminated transparent medium; that's because recollection can take place even when the transparent medium is in its potential state (i.e., when there is no light). Thus, the "alteration" in question must be a real change, though non-standard; or, if the "alteration" of the illuminated transparent medium amounts to color merely appearing through the medium (and such an "alteration" is no alteration) it does not follow that the mediate effect upon the eye is also not a real alteration.

\section{§4.3.3. Communicable Change, Though Non-Standard Change}

Third, the following two passages suggest that we should read the "alteration" in question as real, though non-standard:

[a] mobile animal . . . must perceive not only when it is 
touched, but also from afar. This would be the case if it were able to perceive through a medium, from the medium being acted upon and moved by what is perceptible and the animal in turn by it. For it is just like that which causes motion with respect to place (emphasis mine), which produces change up to a certain point: that which pushes another thing makes the latter push as well; the movement occurs through an intermediary; the first mover pushes without being pushed, while what is last is only pushed and does not push; and intermediaries are many. So it is in the case of alteration as well (emphasis mine), except that it alters something that remains in the same place, like when one presses into wax and it is moved only so far as one has pressed. A stone would not be moved at all, but water would for some distance, while air is moved a great deal and acts and is acted upon, if it remains stable and unified. (DA, 434b25-435a5)

The other sense organs could come to be from elements aside from earth; but they all produce perception by means of perceiving through something else and through a medium, whereas touch involves touching things (hence the very name it bears). To be sure, the other sense organs also perceive by touch, but on account of something other than themselves (emphasis mine). (DA, 435a11-19)

In the first passage, I emphasize that the alteration involved in perceiving something from afar is like locomotion; namely, it's communicative, for as Aristotle says, in locomotion the mover moves an intermediate object, which then communicates that movement to another object. Even though the "alteration" in the case of the transparent medium is non-standard, and even though the air is not moved in terms of locomotion, Aristotle is telling us that the alteration is first communicated from the color to the transparent medium, and then from the transparent medium to the sense organ. If this communication is to be analogous to locomotion in the way Aristotle specifies, then we end up with a process of actual change. Burnyeat's interpretation of the "alteration" as merely appearing through the transparent medium (and so, as no real alteration at all) was meant to block that such a communicative process takes place for Aristotle. But, as we see, Aristotle says otherwise; thus, Burnyeat's interpretation does not look to be right. 
Moreover, the analogy between pressing into wax and "pressing" into air (or the transparent medium) is also suggestive of a communicative process and real change. While the latter pressing is not the same as the former pressing (since, in the former, locomotion takes place and in the latter, it doesn't), the word 'pressing' suggests a change of some sort. For instance, the wax's shape is changed when it is pressed upon; likewise, then, the color impresses a change on the transparent medium. Indeed, in the second passage we learn that all perception comes by touch; thus, the way that all senses operate is through some sort of contact. Concerning vision, how is this contact to be understood? Taking the two passages together, the following is what's suggested. First, the color is in contact with the illuminated transparent medium. Second, the transparent medium is in contact with the eye. Third, it is the nature of color to act upon the illuminated transparent medium, such that the color communicates a nonstandard change to the illuminated transparent medium. Last, non-standard change communicated to the illuminated transparent medium is then communicated to the eye.

\section{$\S 4.4$. The Function of the Transparent Medium}

\section{\$4.4.1. Burnyeat's Interpretation: It Separates}

Here, we would to well to make a small digression before turning to an objection that Burnyeat might make. This is so, because the fact that all perception involves touch (i.e., contact) is not only damaging to his view that no process or real alteration occurs, but it damages another part of his interpretation of the conditions of vision. As Burnyeat states:

[i]t is dangerously easy for us to suppose that the impossibility of direct action by colour on sight is to be explained by the fact that the colour is situated at a distance. The function of the medium is to join the object perceived to the subject perceiving it. The medium is needed to transmit the colour, or information about it, to the sight of the perceiver. (EADA, 426)

Instead of interpreting Aristotle as saying that the transparent medium joins the color to the eye (albeit indirectly), he interprets Aristotle as claiming that the transparent medium separates the color from the eye. He notes that Aristotle's point is that if he color were to directly touch the eye, then the color 
would not be seen. As Burnyeat claims:

[t]his implies that the function of the medium is primarily to separate the object perceived from the perceiving subject (ibid.).

Indeed, this is supposedly why Aristotle takes Democritus' view (i.e., the view that, if there were void between a viewer and a viewable object, then the viewer would see the viewable object with the utmost clarity) to be false:

[b]ut from Aristotle's point of view, if per impossible there was a void, i.e. nothing, between subject and object, then so far as explanation goes the situation would be just like the case where an object is put directly on the eye (EADA, 427).

\section{\$4.4.2. My Criticism: It Joins and Separates}

This, however, has Aristotle either equivocating on 'void' or 'nothing' or not realizing that the eye and color are separate since there is distance between them. If the explanation would be similar to the case where an object is put directly on the eye, then the word 'nothing' must be interpreted as meaning that not only is there no medium (e.g., transparent medium) between the color and the eye, but there must be no distance either; clearly, by 'void' or 'nothing', Democritus does not intend to exclude distance, for the object we would see with the utmost clarity is an ant in the heavens (DA, 419a15-23). If Aristotle isn't equivocating, then there is distance between the color and the eye; a fortiori, the eye and color are separate, which then satisfies the condition Burnyeat has Aristotle giving us for vision to occur. Then Aristotle should claim, however, that we would perceive color when there is void between the color and our eyes. Yet, he claims that we would not. Therefore, it cannot be that the function of the transparent medium is to separate the eye from the color and not join them. Instead, in Aristotelian fashion, it must be that the transparent medium, in one way, separates the eye from the color; yet, in another way, joins the color to the eye. Thus, while it is "easy for us to suppose that the impossibility of direct action by colour on sight is to be explained by the fact that the colour is situated at a distance" (EADA, 426). It is, by no means a dangerous supposition.

Furthermore, it is odd that Burnyeat does not take a different approach. It would be much more natural for him to interpret Aristotle as claiming that the reason we would not see color, if there were void between it and our eyes, is that, without the transparent medium, there is nothing for the color to appear 
through to the perceiver. This would have the benefit of being consistent with Burnyeat's interpretation that there is no real alteration; moreover, it does not force an interpretation onto Aristotle such that he either equivocates over 'void' and 'nothing' or makes him inconsistent. However, we have already seen a few problems with accepting Burnyeat's interpretation.

\section{§4.5. Possible Objections and Possible Responses}

\section{\$4.5.1. Communicable Change Leads to Haphazard Vision}

Turning back to Burnyeat's interpretation that, for Aristotle, color merely appears through the transparent medium, such a view can be defended by objecting that the interpretation we are giving - one that involves communicable change - would have people's field of vision be a haphazard blob of changing colors. For supposing that there is a real change being communicated from the color through the transparent medium to the eye, then, like Burnyeat's example of the bowl of water that is dyed red (i.e. where the water literally changes to being red), the transparent medium should fill up with all of these real changes. In that case, the changes would 1) in some sense (though not a locomotive sense) run into each other, perhaps resulting in some sort of competition between the real changes (e.g. think of what happens when multiple dyes are put in a bowl of water), and 2) people should experience colors in their visual field from objects that are not in front of their eyes; the latter because the colors behind a person's eyes are acting on the transparent medium just as much as the colors in front of a person's eyes, thereby filling the medium up with real changes (e.g. think of a perceiving eye in the bowl of water, where the dye is placed behind it; in that case, the color will eventually communicate in front of the eye and to it).

Burnyeat's interpretation does not run into such a problem, since, on his view, there is no real change. That is, since colors merely appear through the transparent medium, the perceiver will only experience those colors that are appearing through the medium at the perceiver's eyes. Burnyeat can object, then, that any reading of Aristotle that has him claiming that color communicates a real change to the transparent medium saddles Aristotle with an untenable position. And since we ought to give Aristotle a charitable reading, if there is another reading that both is a reasonable reading and doesn't saddle Aristotle with an untenable position, then we ought to take it; namely, we ought to accept his interpretation. 


\section{§4.5.2. Possible Responses: Directionality Defense and Untenable Position}

There are a few responses that might be taken against this move. First, one might claim that, for some of the reasons already given, Burnyeat's interpretation doesn't provide a reasonable reading of Aristotle; in which case, perhaps some third alternative interpretation should be sought and adopted. Second, one might claim that, given enough textual support contrary to the charitable reading, we must sacrifice charity for accuracy; that is, since philosophers have been known, from time to time, to adopt untenable positions, given enough textual support for Aristotle holding an untenable position, then that is probably the accurate reading. Third, one might endeavor to show that the communicable change interpretation doesn't saddle Aristotle with the problem that Burnyeat or others might charge it with. And fourth, one might show that Burnyeat's interpretation would also saddle Aristotle with an untenable position, thereby showing it to be no better than the communicable change interpretation. While there are grounds for thinking that the first two responses would be successful against such an objection (namely, the reasons already provided), it can be shown that the communicable change interpretation doesn't necessarily saddle Aristotle with the problem in question. And, if that can be shown, then the objection can be resisted; moreover, it can be shown that Burnyeat's interpretation also forces Aristotle into an untenable position. First, we will turn to developing an instance of the third type of response. Then we will turn to showing the untenable position with which Burnyeat's interpretation saddles Aristotle.

\section{$\S 4.5 .2 .1$. Directionality Defense}

The problem the objection provides is that, on the communicable change interpretation, it looks like the change will permeate haphazardly throughout the transparent medium. Thus, in providing the response, we will need to rely on the notion of directionality; then we will need to find textual support for taking Aristotle to think that, not only is there communicable change, but that it is directional. First, let's clarify the notion of directionality and why it gets the communicable change interpretation out of the problem.

Imagine a steel cylinder rod that is spiked on one end of it. One property of such an object is that it has a piercing effect, but, assuming that no other object comes toward it, it has the piercing effect only if the spiked end is moving in the direction of another object and makes contact with the other object. The point 
to be taken away from this example (pun intended) is that the piercing effect can only take place if the right part is moving in the right direction; namely, the spiked end moving at the object. For, if the rod were to be swung at the object, then, instead of getting a piercing effect, we would get a blunt-forceeffect; or, if the object in question is only receptive to piercing effects and not to blunt-force-effects, then we would have no effect at all. That the communicable change caused by color must be moving in the right direction at the right part of the eye is one part of what I mean by 'directionality'.

But now imagine a world where the physics of it is like ours, except, instead of there being light, there is smlight. Smlight is very much like light, for both have the directional character explained above, but it is unlike light in that it does not diffuse (or randomly alter course - this is the other part of what I mean by 'directionality'); moreover, both light and smlight have the property that, when it strikes our eyes, we perceive color. As you probably know, if a laser beam of light is beamed through fog, you will see color, since parts of the light beam are diffusing off and traveling to your eye. This is not so with a smlaser beam of smlight; since parts of smlight will not diffuse and travel to your eye, you will not see color when a smlaser beam of smlight is beamed into fog. In fact, the only way to see the color of the smlaser beam is if your eye is directly in the path of the beam, such that your eye is pointed towards it. Thus, if the effect that color has on the transparent medium has directionality as I have just explained it, then the possible objection does not succeed. That's because the perceiving-color-effect that the communicable change has on a perceiver's eye cannot take place unless the perceiver is facing the color from which the perceiving-color-effect is coming from, so, even though the transparent medium is filling up with real changes caused by color, no person's visual field will be a blob of haphazard color. The next question, then, is whether the text supports such a reading.

Consider some of the textual support. First, the analogy between locomotion and the communicable nonstandard change discussed earlier suggests directionality; that's because, when one object bumps into another, the second object moves in the direction from whence it was hit. Second, the analogy between the pressing of wax and the communicable nonstandard change discussed earlier also suggests directionality; that's because, if one wants to impress an object into wax, one will most likely move the object straight at and into the wax. 


\section{$\S 4$ 5.2.2. Burnyeat Saddles Aristotle with an Untenable Position}

Now, even if you don't think the directionality story that I have painted can be plausibly ascribed to Aristotle, I can still show that Burnyeat's interpretation that the transparent medium simply allows the color to appear through it will also saddle Aristotle with an untenable position. On the story I have painted, Aristotle is able to explain why images and colors can be reflected by things with smooth surfaces, such as mirrors or pools of water; that's because, even though it's generally the case that the communicable change is communicated in one direction, such surfaces have the property of redirecting the communication of change in another direction. Burnyeat's interpretation of Aristotle can't explain this phenomenon. That's because no real change happens on his account; the color merely appears through the transparent medium. Thus, if one had one's back to the mirror, the color would appear to that person. But if one were looking at the mirror, one would not see any of the colors behind one's self, for those colors only appear through the transparent medium up to the mirror and up to the back of your head, not to your eyes; that's because the colors behind you do not produce a real change for the mirror to redirect toward your eyes. Therefore, in order to explain reflection of colors and images, Aristotle must postulate a real change of some sort; otherwise, Aristotle's position is untenable, since smooth surfaces, such as mirrors and pools of water, do, in fact, reflect colors.

\section{$\S 5$. Conclusion}

Hence, given all of the considerations in the previous section, I conclude that Burnyeat's interpretation of Aristotle's theory of vision is wrong. It is worth pointing out that, while it casts doubt on his interpretation that, for Aristotle, perception is primitive, it does not follow that because he was wrong about Aristotle's theory of vision that he is also wrong about whether perception is primitive. That's because, even though there is real communicable change being caused by color, and by sensible objects more generally, Burnyeat still might show that, once that change has been communicated up to the eye, the eyeball does not change, but instead, only the awareness changes. However, the fact that he felt pressure to interpret the process of vision as no process at all, suggests that such a maneuver would be hard pressed. Furthermore, my objection in $\S 4.3 .2$ - the recollection in the dark objection - will be particularly difficult for Burnyeat to adequately explain away; for, if Burnyeat's interpretation is correct, then Aristotle should not be evoking motion in the sense organ 
for recollection, especially since, given that recollection can take place in the dark, that motion can't be explained away as color merely appearing through the transparent medium. Thus, the above considerations cast serious doubt on the view that, for Aristotle, perception is primitive; and since it does cast doubt on Burnyeat's interpretation, these considerations help to support Putnam \& Nussbaum's position.

\section{References}

Aristotle. De Anima. Trans. Mark Shiffman. Newburyport: Focus Publishing, 2011.

Burnyeat, M.F. "How Much Happens When Aristotle Sees Red and Hears Middle C?" Essays on Aristotle's De Anima 1995: 422-34.

Burnyeat, M.F. "Is an Aristotelian Philosophy of Mind Still Credible? (A Draft)." Essays on Aristotle's De Anima 1995: 15-26.

Cohen, S. Marc. "Hylomorphism and Functionalism." Essays on Aristotle's De Anima 1995: 57-73.

Nussbaum, Martha C. and Putnam Hilary. "Changing Aristotle's Mind.” Essays on Aristotle's De Anima 1995: 27-73.

Wilkes, K.V. "Psuchē Versus the Mind.” Essays on Aristotle’s De Anima 1995: 10927. 